\title{
The diagnostic suitability of a xerostomia questionnaire and the association between xerostomia, hyposalivation and medication use in a group of nursing home residents
}

\author{
Gert-Jan van der Putten • Henk S. Brand • \\ Jos M. G. A. Schols • Cees de Baat
}

Received: 3 August 2009 / Accepted: 7 January 2010 /Published online: 18 February 2010

(C) The Author(s) 2010. This article is published with open access at Springerlink.com

\begin{abstract}
The study objective was to explore the diagnostic suitability of the Xerostomia Inventory and the association between xerostomia, hyposalivation and medication use in a group of nursing home residents. A cross-sectional study was carried out in 50 physically impaired nursing home residents (20 men) with a mean age of 78.1 years (range, 53-98) in The Netherlands. The Xerostomia InventoryDutch version was completed for all residents and the data were subjected to exploratory factor analysis to determine the diagnostic suitability. Residents' data on xerostomia, whole saliva secretion rates and hyposalivation-related medications used were collected and statistically analyzed. The diagnostic suitability of the Xerostomia InventoryDutch version appeared restricted. The prevalence of xerostomia was $52 \%$, without gender and age difference. The prevalence of hyposalivation was $24 \%$ for resting, $60 \%$ for chewing-stimulated and $18 \%$ for acid-stimulated whole
\end{abstract}

G.-J. van der Putten

BENECOMO, Flemish-Netherlands Geriatric

Oral Research Group and Zorgaccent Amersfoort,

Amersfoort, The Netherlands

H. S. Brand

Department of Dental Basic Sciences,

Academic Centre for Dentistry Amsterdam,

Amsterdam, The Netherlands

J. M. G. A. Schols

BENECOMO, Flemish-Netherlands Geriatric Oral Research

Group and Department of General Practice, Maastricht University,

Maastricht, The Netherlands

C. de Baat $(\bowtie)$

BENECOMO, Flemish-Netherlands Geriatric Oral Research

Group and Department of Oral Function and Prosthetic Dentistry,

Radboud University Nijmegen Medical Centre,

P.O. Box 9101, 6500 HB Nijmegen, The Netherlands

e-mail: c.debaat@dent.umcn.nl saliva. All whole saliva secretion rates were significantly lower in women than in men and in older than in younger residents. Forty-four percent of all medications used were hyposalivation-related and women used significantly more medications than men. Xerostomia was significantly negatively correlated with the resting whole saliva secretion rate. The number of hyposalivation-related medications used was not significantly correlated with the various whole saliva secretion rates. In nursing home residents, xerostomia, hyposalivation and using hyposalivation-related medications seem common and partially associated features.

Keywords Xerostomia $\cdot$ Hyposalivation $\cdot$ Medication . Nursing home $\cdot$ Xerostomia Inventory

\section{Introduction}

Presumably, more than $30 \%$ of the population of 65 years of age and older are experiencing xerostomia, subjective oral dryness $[1,2]$. Due to lack of studies in general population-based samples, a literature review on the prevalence of xerostomia was not conclusive: $13-26 \%$ for men and $20-46 \%$ for women [3]. Data on xerostomia prevalence in frail and institutionalized elderly patients are scarce as well. The few studies established, reported higher figures when compared with the before-mentioned literature review [3]. In a cohort of 99 institutionalized elderly patients with a mean age of 82.5 years, $51 \%$ had noticed subjective symptoms of xerostomia [4]. In groups of frail elderly home-living and hospitalized patients, the prevalence of xerostomia was $57 \%$ and $63 \%$, respectively [5].

A significant number of patients with complaints of xerostomia are not showing objectively assessed salivary hypofunction (hyposalivation) [1, 6]. It has been suggested 
that the visco-elastotic properties of their whole saliva may have altered, for instance by diminished minor salivary gland secretion, failing to lubricate the mouth properly [6, 7]. Another theory suggested is that the patient's perception mechanisms may have altered [6].

To maintain good oral and general health, an adequate amount of saliva should be secreted [6, 8]. Hyposalivation may contribute to several oral complaints, such as xerostomia, generalized oral discomfort, burning mouth and tongue, traumatic oral lesions, halitosis, intolerance to acidic and spicy foods, poor retention of dentures, disturbances in taste and mastication, polydipsia, dysgeusia, dysphasia and dysphonia [9-12]. Hyposalivation may induce tooth wear, oral soft tissue lesions and microorganism colonisation, inducing caries, candidiasis and less frequently periodontal disease [8, 11-14]. Oral complaints and symptoms due to hyposalivation are contributing to reduced quality of life $[15,16]$.

A review study on salivary gland function and ageing reported age-related resting whole saliva secretion decrease, but mixed results of stimulated whole saliva secretion rates [1]. The results of two subsequent studies suggested an age-related reduction of stimulated whole saliva secretion in women [17, 18]. In several studies, older people showed statistically significant reduced resting whole saliva secretion rates, when compared with younger people [19-21].

Histomorphometric examination of salivary gland tissue demonstrated a decrease in the acinar volume, an increase in the ductal volume and replacement of acinar cells with adipose and fibrotic tissues during ageing [1, 22]. In labial salivary glands, the mean volume fraction of seromucous and mucous acinar cells showed statistically significant lower values in elderly people when compared with younger people. The mean seromucous and mucous volume fractions were decreased in the elderly by $49 \%$ and $28 \%$, respectively [23]. It was hypothesized that, nevertheless, most of the salivary gland functions in the elderly are carried out uncomplicated due to the fact that the remaining acinar cells are structurally intact, retain their functional efficiency and are sufficient in quantity. In other words: a secretory reserve may exist to preserve adequate salivary gland function despite the loss of acinar cells [1, 20, 24]. Statistically significant age-related decreases of major and minor salivary glands secretion rates were obvious in several studies $[1,25,26]$. However, some prospective and longitudinal studies showed that the function of major and minor salivary glands was not age-related [1, 18, 27].

Nagler and Hershkovich (2005) suggested that the reduced resting whole saliva secretion rates in a study group of elderly people were due to the fact that some people received medications for age-related diseases [20]. In a group of elderly people, anticholinergic medication use was common and the prevalence of xerostomia was statistically significant higher in those using anticholinergic medications [28]. In another study, users of medications displayed statistically significant reduced resting and stimulated saliva secretion rates of the major salivary glands when compared to non-users [29]. As reported by several investigators previously, hyposalivation seems mainly a consequence of medication use, systemic diseases, head and neck radiotherapy, Sjögren syndrome and/or dehydration [1, 2, 6, 30, 31].

Because of the subjective scope, xerostomia can only be assessed by questioning, using discriminative questions. During the last decades, several questionnaires have been developed [30]. A frequently used questionnaire in research projects on xerostomia is the Xerostomia Inventory [32]. Eleven items of the Xerostomia Inventory are covering both experiential and behavioural aspects of xerostomia (Table 1). Scores to the 11 items are summated, providing a single score representing the subjective severity of xerostomia. The questionnaire has shown acceptable content and concurrent validity, responsiveness, temporal stability and longitudinal construct validity [32-34]. The Xerostomia Inventory has
Table 1 Items of the Xerostomia Inventory-Dutch version and their Pearson's correlation coefficients $(R)$ with the latent variable 'xerostomia'

\begin{tabular}{lll}
\hline Item number & Proposition & $R$ \\
\hline 1 & I sip liquids to aid in swallowing food & 0.55 \\
2 & My mouth feels dry when eating a meal & 0.63 \\
3 & I get up at night to drink & - \\
4 & My mouth feels dry & 0.62 \\
5 & I have difficulty in eating dry foods & 0.63 \\
6 & I suck sweets or cough lollies to relieve dry mouth & 0.37 \\
7 & I have difficulties swallowing certain foods & 0.61 \\
8 & The skin of my face feels dry & 0.58 \\
9 & My eyes feel dry & 0.49 \\
10 & My lips feel dry & 0.68 \\
11 & The inside of my nose feels dry & - \\
\hline
\end{tabular}


already been used for examining the association between medication exposure and severity of xerostomia in older people [34, 35].

Although xerostomia is not related to hyposalivation obviously, it is a symptom which deserves attention of oral health care and other health care professionals because of its feasible great impact on oral health, general health and quality of life. Certain items or a certain summated score of the Xerostomia Inventory may be indicative of hyposalivation, directing towards objective assessment and eventually management of hyposalivation.

The aim of this study was exploring the diagnostic suitability of the Xerostomia Inventory and the association between xerostomia, hyposalivation, and medication use in nursing home residents. Four objectives were formulated. The first objective was to examine the diagnostic suitability of a Dutch translation of the Xerostomia Inventory for determining the severity of xerostomia. A second objective was to assess the prevalence of xerostomia, the prevalence of hyposalivation, the number of hyposalivation-related medications used, and gender and age differences of these three variables. The third objective was to determine the correlation of xerostomia with whole saliva secretion rates. The fourth objective was to determine the correlation of the number of hyposalivation-related medications used with whole saliva secretion rates.

\section{Material and methods}

A cross-sectional study was carried out in a group of physically impaired nursing home residents. The study design was reviewed and approved by the Medical Ethic Committee of the Netherlands. All subjects gave informed written consent about their participation in the study.

\section{Study group}

The original study group consisted of 55 physically impaired residents of a nursing home in The Netherlands. The nursing home was not diverging from all nursing homes in The Netherlands with respect to age, gender, medical diagnoses, comorbidity, dependency and length of stay of the residents. Three residents decided not to participate and two suffered from apraxia and were excluded consequently. Additional exclusion criteria were: terminally ill, cognitive impairment, fever, dehydration, Sjögren's syndrome, and previously received radiotherapy in the head and neck region. None of the 50 residents $(20$ men) remaining from the original study group, did meet one or more of the additional exclusion criteria. Their mean age was 78.1 years (range, 53-98). The mean age of the men was 76.8 years and of the women 79.0 years, a not statistically significant difference. Nine participating residents were younger than 70 years of age, 25 were in the age group 70-80, and 16 were older than 80 years of age.

\section{Xerostomia}

The original English version of the Xerostomia Inventory was translated into Dutch following the repeated backtranslation procedure. The response options to the 11 propositions of the Xerostomia Inventory are 'never', 'hardly ever', 'occasionally', 'fairly often' or 'very often'. Preceding the main study, a pilot study was carried out in 15 physically impaired nursing home residents to examine the ability of the residents to discriminate between the five response options. The pilot study revealed that the residents were experiencing several discriminating problems. Consequently, it was decided to reduce the number of response options from 5 to 3: 'never' (score 1), 'occasionally' (score 2) and 'ever' (score 3). The thus modified Xerostomia Inventory is called Xerostomia Inventory-Dutch version and the summated score of this version is called Summated Xerostomia Inventory-Dutch version. The Summated Xerostomia Inventory-Dutch version represents a resident's experienced severity of xerostomia, providing a score between 11 and 33 .

For all participating residents a Xerostomia InventoryDutch version questionnaire was completed and the Summated Xerostomia Inventory-Dutch version was assessed.

\section{Whole saliva secretion rates}

Saliva was collected from all participating residents. The collecting time was between 9:30 AM and 12:30 PM to avoid circadian effects [36]. The residents were instructed to refrain from eating, smoking and drinking coffee and tea during $1.5 \mathrm{~h}$ prior to the saliva collection. Drinking tap water was permitted. During the saliva collection, the residents were requested to seat straight and to refrain from speaking and swallowing. Resting and stimulated whole saliva's were collected according to the spitting method by spitting all oral fluid currently available in the mouth, into a pre-weighed test tube [37]. First, resting whole saliva was collected during $5 \mathrm{~min}$. Every $30 \mathrm{~s}$ the residents spitted the oral fluid available in the mouth. After a 2-min break, chewing-stimulated whole saliva was collected during 5 min using a tasteless piece of Parafilm $(5 \times 5 \mathrm{~cm} ; 0.3 \mathrm{~g})$. Every $30 \mathrm{~s}$ the residents spitted the oral fluid available in the mouth. Finally, after another 2-min break, acidstimulated whole saliva was obtained by sweeping the tongue margins and tongue tip with a cotton swab soaked in a $4 \%$ citric acid solution every $20 \mathrm{~s}$. During $2 \mathrm{~min}$ the residents spitted every $20 \mathrm{~s}$ the oral fluid available in the 
mouth. All oral fluid volumes were determined gravimetrically, assuming $1 \mathrm{~g}$ as equivalent to $1 \mathrm{ml}$ whole saliva.

The hyposalivation cut-off values used were $0.1 \mathrm{ml} / \mathrm{min}$ for resting whole saliva and $0.5 \mathrm{ml} / \mathrm{min}$ for chewingstimulated as well as acid-stimulated whole saliva [1].

Hyposalivation-related medications used

Groups of medications most commonly indicated as cause of hyposalivation have been listed by Scully (2003) [31]. From the residents' medical records, all and hyposalivationrelated [31] medications were registered.

Statistical analysis

The Xerostomia Inventory-Dutch version data were subjected to exploratory factor analysis to reveal the range of the 11 proposition responses, possibly providing one latent variable determining the severity of xerostomia.

For determining the correlation of xerostomia and the number of hyposalivation-related medications used with whole saliva secretion rates, the residents' whole saliva secretion rates were dichotomized: below and equal or above the hyposalivation cut-off values.

To assess possible correlations of (1) xerostomia, whole saliva secretion rates as well as the number of hyposalivationrelated medications used with gender and age, (2) xerostomia with whole saliva secretion rates, and (3) the number of hyposalivation-related medications used with whole saliva secretion rates, additional statistical analysis was performed by analysis of variance ((M) ANOVA) using SPSS-pc version 14.0 (SPSS Inc. Chicago, IL, USA). A $P$ value of 0.05 was considered to be statistically significant.

\section{Results}

Xerostomia Inventory-Dutch version

Exploratory factor analysis of the Xerostomia InventoryDutch version data resulted in four eigenvalues higher than 1 and one eigenvalue higher than 3, respectively, 1.09, 1.23, 1.29 and 3.71. The eigenvalue of 3.71 represented a factor providing a single latent variable for xerostomia. The factor load showing the Pearson's correlation coefficients of all Xerostomia Inventory-Dutch version items with the latent variable 'xerostomia' is shown in Table 1. Xerostomia Inventory-Dutch version items 3 and 11 did not show any correlation with the latent variable 'xerostomia'. Items 2, 4, 5, 7 and 10 demonstrated Pearson's correlation coefficients above 0.6. Varimax rotation and 0.35 as maximal convergence for iteration were used. The stronger the correlation of an item with the factor 'xerostomia', the more frequent 'ever' (score 3) was responded to that particular item. The weaker the correlation of an item with the factor 'xerostomia', the more frequent 'never' (score 1) was responded to that particular item.

\section{Xerostomia}

The Xerostomia Inventory-Dutch version item scores and mean item scores are presented in Table 2. The mean Summated Xerostomia Inventory-Dutch version score was $16.5(\mathrm{SD}=4.2)$. Based on scores 2 and 3 to Xerostomia Inventory-Dutch version item 4 ('My mouth feels dry'), the prevalence of xerostomia was $52 \%$. Statistically significant gender differences of xerostomia prevalence were not observed (men 50\%, women 53\%; Chi-square test: $P=$ 0.82 ). Although xerostomia was more prevalent in residents older than 80 years of age $(69 \%)$ than in younger residents (44\%), the difference failed to reach significance (Chisquare test: $P=0.10$ ).

\section{Whole saliva secretion rates}

The data of resting whole saliva, chewing-stimulated whole saliva and acid-stimulated whole saliva are presented as mean values with standard deviations in Tables 3 and 4 .

The mean resting whole saliva and acid-stimulated whole saliva, $0.2(\mathrm{SD}=0.2)$ and $1.2(\mathrm{SD}=0.9) \mathrm{ml} / \mathrm{min}$, respectively, were somewhat above the hyposalivation cutoff values. The mean chewing-stimulated whole saliva of $0.5(\mathrm{SD}=0.5) \mathrm{ml} / \mathrm{min}$ was equal to the hyposalivation cutoff value (Table 3 ). In $48 \%$ of the residents, the resting whole saliva was less than 0.2 and in $24 \%$ less than $0.1 \mathrm{ml} / \mathrm{min}$. The chewing- and acid-stimulated whole saliva were less

Table 2 Xerostomia Inventory-Dutch version item scores and mean item scores $(n=50)$

\begin{tabular}{lcrrr}
\hline Item number & $\begin{array}{l}\text { Never } \\
\text { Score 1 }\end{array}$ & $\begin{array}{l}\text { Occasionally } \\
\text { Score 2 }\end{array}$ & $\begin{array}{l}\text { Ever } \\
\text { Score 3 }\end{array}$ & Mean score \\
\hline 1 & 24 & 12 & 14 & 1.8 \\
2 & 35 & 8 & 7 & 1.4 \\
3 & 32 & 7 & 11 & 1.6 \\
4 & 24 & 13 & 13 & 1.8 \\
5 & 34 & 7 & 9 & 1.5 \\
6 & 37 & 11 & 2 & 1.3 \\
7 & 37 & 9 & 4 & 1.3 \\
8 & 34 & 11 & 5 & 1.4 \\
9 & 39 & 7 & 4 & 1.3 \\
10 & 21 & 20 & 9 & 1.8 \\
11 & 40 & 8 & 2 & 1.2 \\
\hline
\end{tabular}


Table 3 Mean secretion rates ( $\mathrm{ml} / \mathrm{min})$ and standard deviations $( \pm$ ) of resting whole saliva (RWS), chewing-stimulated whole saliva (CH-SWS) and acid-stimulated whole saliva (A-SWS), separately for men and women and for age group $(<70 ; 70-80 ;>80)$

\begin{tabular}{llllll}
\hline $\begin{array}{l}\text { Whole saliva type } \\
\text { (cut-off value for hyposalivation) }\end{array}$ & $\begin{array}{l}\text { men } \\
n=20\end{array}$ & $\begin{array}{l}\text { women } \\
n=30\end{array}$ & $\begin{array}{l}\text { all } \\
n=50\end{array}$ & $\begin{array}{l}<70 \\
n=8\end{array}$ & $\begin{array}{l}70-80 \\
n=25\end{array}$ \\
\hline RWS (0.1) & $0.4 \pm 0.2$ & $0.1 \pm 0.1$ & $0.2 \pm 0.2$ & $0.3 \pm 0.2$ & $0.2 \pm 0.2$ \\
CH-SWS (0.5) & $0.8 \pm 0.6$ & $0.4 \pm 0.5$ & $0.5 \pm 0.5$ & $0.6 \pm 0.7$ & $0.5 \pm 0.5$ \\
A-SWS (0.5) & $1.6 \pm 1.0$ & $0.9 \pm 0.6$ & $1.2 \pm 0.9$ & $1.3 \pm 0.8$ & $1.2 \pm 1.0$ \\
\hline
\end{tabular}

than $0.5 \mathrm{ml} / \mathrm{min}$ in $60 \%$ and $18 \%$ of the residents, respectively.

The mean values of resting whole saliva, chewing- and acid-stimulated whole saliva were lower in women, when compared to men (Table 3). The mean chewing-stimulated whole saliva in women of $0.4(\mathrm{SD}=0.5) \mathrm{ml} / \mathrm{min}$ was below the hyposalivation cut-off value. The differences between men and women were statistically significant, even after correction for age and the number of hyposalivation-related medications used (ANOVA; USW: $P<0.01$; chewing- and acid-stimulated whole saliva: $P<0.05$ ).

Age was statistically significant negatively correlated with resting whole saliva, chewing- and acid-stimulated whole saliva after correction for gender and number of hyposalivation-related medications used (ANOVA; USW: $P<0.05$; chewing- and acid-stimulated whole saliva: $P=$ $0.05)$. The mean chewing-stimulated whole saliva of the people older than 80 years of age of $0.4(\mathrm{SD}=0.3) \mathrm{ml} / \mathrm{min}$ was, although not statistically significant, lower than the hyposalivation cut-off value (Table 3 ).

\section{Hyposalivation-related medications used}

The total number of all types of medications used at the time of the investigation was 207 and the number of hyposalivation-related medications used was 91 (Table 5). This means that $44 \%$ of all medications used were hyposalivation-related.

All except one resident used one or more medications. The mean number of all types of medications used by the 49 residents was $4.2(\mathrm{SD}=2.6)$. Twenty-seven residents used hyposalivation-related medications, with a mean number of $3.4(\mathrm{SD}=2.2)$. The numbers of both all types of medications and hyposalivation-related medications used by the 49 and 27 residents respectively were statistically significant higher in women when compared with men (Chi-square test: $P<0.01$ and $P<0.05$, respectively). An age difference could not be detected.

Correlation of xerostomia with whole saliva secretion rates

The scores to the Xerostomia Inventory-Dutch version items 2 and 4 in relation to mean scores and standard deviation of resting whole saliva, chewing- and acidstimulated whole saliva are shown in Table 4. ANOVA revealed that scores 2 and 3 to Xerostomia Inventory-Dutch version items 2 and 4 were statistically significant negatively correlated with resting whole saliva (item 2: $P<0.01$; item 4: $P<0.05$ ). Scores 3 to items 2 and 4 were correlated with resting whole saliva below the hyposalivation cut-off value, respectively in all cases for item 2 and in $78 \%$ of cases for item 4 . Of those residents who scored 1 to Xerostomia Inventory-Dutch version item 4, 33\% had resting whole saliva below the hyposalivation cut-off value. Statistically significant gender and age differences could not be demonstrated.

Correlation of number of hyposalivation-related medications used with whole saliva secretion rates

No statistically significant correlation could be assessed between on the one hand the number of hyposalivationrelated medications used and on the other hand resting whole saliva, chewing- and acid-stimulated whole saliva (ANOVA: $P=0.23, P=0.13$ and $P=0.09$ respectively).

\section{Discussion}

Exploratory factor analysis of the Xerostomia InventoryDutch version data showed one latent variable for xero-

Table 4 Scores of the 50 residents to items 2 and 4 of the Xerostomia Inventory-Dutch version (XI-D) in relation to mean scores $(\mathrm{ml} / \mathrm{min})$ and standard deviations $( \pm$ ) of resting (RWS), chewing-stimulated (CH-SWS) and acid-stimulated (A-SWS) whole saliva secretion rates

\begin{tabular}{lrrlll}
\hline XI-D-item & Score & $\mathrm{n}$ & \multicolumn{4}{l}{ Secretion rates } \\
\cline { 3 - 6 } & & & RWS & CH-SWS & A-SWS \\
\hline 2 & 1 & 35 & $0.3 \pm 0.2$ & $0.5 \pm 0.5$ & $1.2 \pm 1.0$ \\
2 & 2 & 8 & $0.3 \pm 0.2$ & $0.7 \pm 0.7$ & $1.2 \pm 0.6$ \\
2 & 3 & 7 & $0.1 \pm 0.1$ & $0.5 \pm 0.3$ & $1.1 \pm 0.6$ \\
4 & 1 & 24 & $0.3 \pm 0.2$ & $0.5 \pm 0.5$ & $1.3 \pm 1.1$ \\
4 & 2 & 13 & $0.2 \pm 0.2$ & $0.5 \pm 0.3$ & $1.0 \pm 0.4$ \\
4 & 3 & 13 & $0.2 \pm 0.2$ & $0.7 \pm 0.6$ & $1.4 \pm 0.7$ \\
\hline
\end{tabular}


Table 5 Hyposalivation-related medications used by the residents

\begin{tabular}{lc}
\hline Medication & Number used \\
\hline Anticholinergic medications & 5 \\
Alpha receptor antagonists for treatment & \\
$\quad$ of urinary retention & 8 \\
Antipsychotics, such as phenotiazines & 9 \\
Diuretics & 4 \\
$\quad$ Antihistamines & \\
Sympathomimetic medications & 24 \\
Antihypertensive agents & 7 \\
Antidepressants; serotonin agonists & \\
$\quad$ or noradrenaline and/or serotinine & \\
$\quad$ re-uptake inhibitors & 12 \\
Bronchodilatators & 1 \\
Skeletal muscle relaxants & 11 \\
Benzodiazepines, hypnotics, opioids & \\
and medications of abuse \\
H2 antagonists and proton pump inhibitors \\
Cytotoxic medications
\end{tabular}

stomia and the factor load showed only relevant Pearson's correlation coefficients with the items 2, 4, 5, 7 and 10 . Based on these results, the diagnostic suitability of the Xerostomia Inventory-Dutch version seems restricted. A modified Xerostomia Inventory-Dutch version containing only items 2, 4, 5, 7 and 10 might be a suitable inventory of the severity of xerostomia symptoms, which deserves further scientific exploration.

The variable 'experiencing dry mouth' has been used in several studies to diagnose xerostomia [3]. Item 4 of the Xerostomia Inventory-Dutch version is representing this variable. Fifty-two per cent of the residents responded item 3 ('My mouth feels dry') by score 2 (occasionally) or 3 (ever). It was assumed that these two scores were representing the xerostomia prevalence of the present study group. The figure of $52 \%$ is within the range of the figures of previous studies on prevalence of xerostomia in groups of institutionalized elderly people (35-63\%) and somewhat higher than in groups of non-institutionalized elderly people $(21-46 \%)[3-5,35,38]$.

The mean Summated Xerostomia Inventory-Dutch version (16.5) is a scarcely relevant outcome because of the restricted diagnostic suitability of the Xerostomia Inventory-Dutch version, as concluded in the present study.

Contrary to the results of some previous studies in mainly elderly people $[1,3,7,39,40]$, but in accordance with the result of one previous study in younger adults [41], xerostomia showed no gender-difference in the present study. The not conclusive results of previous studies and the present study are probably due to age-differences, limited sample sizes, methodological differences and diagnostic criteria used.
Women had a statistically significant lower mean resting whole saliva secretion rate when compared to men. This phenomenon has also been reported in several previous studies [1, 11, 31, 42]. It has been suggested that the menopause and female hormone oestrogen are influencing the salivary function in common with many other physiological and psychological functions. However, the results of reports on the correlation of menopause, oestrogen, and menopausal hormonal replacement therapy with the various saliva secretion rates are not conclusive [18, 25, 43].

Age-related resting whole saliva secretion decrease occurs unarguably, especially in elderly people [1]. However, it is not yet revealed which percentage of (institutionalized) elderly people are suffering from resting whole saliva secretion rates below the hyposalivation cut-off value. In the present study group of physically impaired nursing home residents, this figure was $24 \%$. Similar results were reported in two studies in non-institutionalized elderly people (20-29\%) [21, 32].

It is hardly possible to compare the data of hyposalivationrelated medications used in the present study group with similar groups of patients because of scarceness of literature reports. In a more than 20 years old study, 761 institutionalized elderly people were taking on average four medications (present study group $4.2 ; \mathrm{SD}=$ 2.6) and $47 \%$ of them were taking one or more hyposalivation-related medications [44]. Thomson et al. (2000) found a mean number of $3.2(\mathrm{SD}=2.6)$ medications used in a group of non-institutionalized elderly people, but no distinction was made between types of medications, gender and age [34]. The results of the present study are confirming that many nursing home residents are using (several) hyposalivation-related medications. Probably, these medication use figures would have been higher when also cognitively impaired elderly people had been included in the present study.

Thirty-three per cent of the study group had score 1 (never) to the Xerostomia Inventory-Dutch version item 4 ('My mouth feels dry'), whereas their resting whole saliva was below the cut-off value. Explanations proposed for this disparity are that alterations have occurred in patient's perception mechanisms and that the questions diagnosing xerostomia are not satisfactory $[1,6,7]$. Due to the specific character of the present study group, additional explanations may be: overshadowing of the problem by more intensive problems, having found ways to compensate hyposalivation (e.g. drinking while eating), and adaptation to, acceptance of, and resignation to the feeling of oral dryness.

Items 2 and 4 of the Xerostomia Inventory-Dutch version showed a statistically significant correlation with hyposalivation, defined as resting whole saliva secretion rate below $0.1 \mathrm{ml} / \mathrm{min}$. Positive responses to these two 
items may be a satisfactory and adequate indication for clinical assessment of hyposalivation by sialometry.

The number of hyposalivation-related medications used was not statistically significant correlated with the whole saliva secretion rates. This study result suggests that in patients using several hyposalivation-related medications, reducing the number of these medications is not an adequate recommendation to increase whole saliva secretion rates. Discontinuing the use of hyposalivation-related medications, if possible and well-considered, may be the sensible recommendation of choice.

Apart from the common limitations of clinical studies (in impaired elderly human subjects), the present study had some specific limitations. First, the number of subjects participating was limited. Second, the study group was very selective and restricted to physically impaired nursing home residents. In addition, the Xerostomia InventoryDutch version was not used and scientifically examined previously. Consequently, the results of the study should be interpreted carefully.

Xerostomia and hyposalivation may alter a patient's oral health and quality of life $[15,16]$. In order to anticipate this problem, a good recommendation is drinking regularly and eating highly fluid-containing food [30]. Hyposalivation due to medication may be treated by altering the dosage of the medication or by replacing the medication by an equally effective, but not or less hyposalivation-inducing medication [30]. Also gustatory and mechanical salivary stimulating techniques may be helpful to relieve the feelings of xerostomia, such as consuming sugar-free chewing gum, candies, and mints, as well as acidic drinks and foods [30, 45]. Systemic medication of pilocarpine or cevimeline or application of physostigmine to the oral mucosal surface may improve saliva secretion, but the possible side effects should be determined and, if possible, anticipated or controlled [42, 46, 47]. When stimulating salivary secretion is not possible or not adequate, symptomatic relief of the oral complaints becomes the primary management strategy. Saliva substitutes, lubricating oral gel and intra-oral reservoirs of saliva substitutes may be used [48].

Frequent oral evaluations and oral hygiene instructions are essential to prevent caries and other oral infections in hyposalivation-related medications using (institutionalized) elderly people. Daily topical fluoride use and antimicrobial mouth rinses may help preventing caries [30, 49].

With regard to the four objectives and within the limitations of the present study, the results are justifying some conclusions.

- The diagnostic suitability of the Xerostomia InventoryDutch version seems restricted and a modified version containing only items 2, 4, 5, 7 and 10 might be a suitable inventory of the severity of xerostomia.
- The prevalence of xerostomia was $52 \%$, without gender and age difference.

- The prevalence of hyposalivation was $24 \%$ for resting whole saliva, $60 \%$ for chewing-stimulated whole saliva and $18 \%$ for acid-stimulated whole saliva; all whole saliva secretion rates were statistically significant lower in women than in men and in older than in younger residents.

- Forty-four per cent of all medications used were hyposalivation-related; the mean number of hyposalivationrelated medications used by 27 residents was 3.4 $(\mathrm{SD}=2.2)$; the number of hyposalivation-related medications used was statistically significant higher in women when compared to men.

- Xerostomia was statistically significant negatively correlated with the resting whole saliva secretion rate.

- The number of hyposalivation-related medications used was not statistically significant correlated with the various whole saliva secretion rates.

The results of the present study are one step forward in exploring the association between xerostomia, hyposalivation, and medication use, but the issue deserves further attention scientifically and clinically.

\section{Conclusions}

The diagnostic suitability of the Xerostomia Inventory-Dutch version seems restricted. Xerostomia, hyposalivation and using hyposalivation-related medications seem common and partially associated features in nursing home residents.

Conflict of interest The authors declare that they have no conflict of interest.

Open Access This article is distributed under the terms of the Creative Commons Attribution Noncommercial License which permits any noncommercial use, distribution, and reproduction in any medium, provided the original author(s) and source are credited.

\section{References}

1. Sreebny LM (2000) Saliva in health and disease: an appraisal and update. Int Dent J 50:140-161

2. Ship JA, Pillemer SR, Baum BJ (2002) Xerostomia and the geriatric patient. J Am Geriatr Soc 50:535-543

3. Orellana MF, Lagravère MO, Boychuk DGJ, Major PW, FloresMir C (2006) Prevalence of xerostomia in population-based samples: a systematic review. J Public Health Dent 66:152-158

4. Dormenval V, Budtz-Jørgensen E, Mojon P, Bruyère A, Rapin C-H (1998) Associations between malnutrition, poor general health and oral dryness in hospitalized elderly patients. Age Ageing 27:123-128

5. Pajukoski H, Meurman JH, Halonen P, Sulkava R (2001) Prevalence of subjective dry mouth and burning mouth in 
hospitalized elderly patients and outpatients in relation to saliva, medication, and systematic diseases. Oral Surg Oral Med Oral Pathol Oral Radiol Endod 92:641-649

6. Eveson JW (2008) Xerostomia. Periodontology 2000(48):85-91

7. Eliasson L, Birkhed D, Carlén A (2009) Feeling of dry mouth in relation to whole and minor gland saliva secretion rate. Arch Oral Biol 54:263-267

8. Dawes C (2008) Salivary flow patterns and the health of hard and soft oral tissues. J Am Dent Assoc 139:18S-24S

9. Mese H, Matsuo R (2007) Salivary secretion, taste and hyposalivation. J Oral Rehabil 34:711-723

10. Van den Broek AMWT, Feenstra L, De Baat C (2007) A review of the current literature on aetiology and measurement methods of halitosis. J Dent 35:627-635

11. Kagami H, Wang S, Hai B (2008) Restoring the function of salivary glands. Oral Dis 14:15-24

12. Kaplan I, Zuk-Paz L, Wolff A (2008) Association between salivary flow rates, oral symptoms, and oral mucosal status. Oral Surg Oral Med Oral Pathol Oral Radiol Endod 106:235-241

13. Almståhl A, Wikström A (1999) Oral microflora in subjects with reduced salivary secretion. J Dent Res 78:1410-1416

14. Bardow A, Nyvad B, Nauntofte B (2001) Relationships between medication intake, complaints of dry mouth, salivary flow rate and composition, and the rate of tooth demineralization in situ. Arch Oral Biol 46:414-423

15. Ikebe K, Matsuda K, Morii K, Wada K, Hazeyama T, Nokubi T et al (2007) Impact of dry mouth and hyposalivation on oral healthrelated quality of life of elderly Japanese. Oral Surg Oral Med Oral Pathol Oral Radiol Endod 103:216-222

16. Mariño R, Schofield M, Wright $\mathrm{C}$, Calache H, Minichiello V (2008) Self-reported and clinically determined oral health status predictors for quality of life in dentate older migrant adults. Community Dent Oral Epidemiol 36:85-94

17. Streckfus C, Bigler L, O'Bryan T (2002) Aging and salivary cytokine concentrations as predictors of whole saliva flow rates among women. A preliminary study. Gerontology 48:282-288

18. Eliasson L, Carlén A, Laine M, Birkhed D (2003) Minor gland and whole saliva in postmenopausal women using a low potency oestrogen (oestriol). Arch Oral Biol 48:511-517

19. Fenoll-Palomares C, Muñoz Mantagud JV, Sanchiz V, Herreros B, Hernández V, Mínquez M et al (2004) Unstimulated salivary flow rate, $\mathrm{pH}$, and buffer capacity of saliva in healthy volunteers. Rev Esp Enferm Dig 96:773-783

20. Nagler RM, Hershkovich O (2005) Age-related changes in unstimulated salivary function and composition and its relations to medications and oral sensorial complaints. Aging Clin Exp Res 17:358-366

21. Flink H, Bergdahl M, Tegelberg Å, Rosenblad A, Lagerlöf F (2008) Prevalence of hyposalivation in relation to general health, body mass index and remaining teeth in different age groups of adults. Community Dent Oral Epidemiol 36:523-531

22. Kim S-K, Allen ED (1994) Structural and functional changes in salivary glands during aging. Microsc Res Tech 28:243-253

23. Vered M, Buchner P, Boldon P, Dayan D (2000) Age-related histomorphometric changes in labial salivary glands with special reference to the Acinar component. Exp Gerontol 35:1075-1084

24. Ghezzi EM, Ship JA (2003) Aging and secretory reserve capacity of major salivary glands. J Dent Res 82:844-848

25. Ghezzi EM, Wagner-Lange LA, Schork MA, Metter EJ, Baum BJ, Streckfus CF et al (2000) Longitudinal influence of age, menopause, hormone replacement therapy, and other medications on parotid flow rates in healthy women. J Gerontol A Biol Sci Med Sci 55:M34-M42

26. Patel PS, Ghezzi EM, Ship JA (2001) Xerostomic complaints induced by an anti-sialogogue in healthy young vs. older adults. Spec Care Dent 21:176-181
27. Eliasson L, Birkhed D, Österberg T, Carlén A (2006) Minor salivary gland secretion rates and immunoglobulin $\mathrm{A}$ in adults and the elderly. Eur J Oral Sci 114:494-499

28. Ness J, Hoth A, Barnett MJ, Shorr RI, Kaboli PJ (2006) Anticholinergic medications in community-dwelling older veterans: prevalence of anticholinergic symptoms, symptoms burden, and adverse drug events. Am J Geriatr Pharmacother 4:42-51

29. Wolff A, Zuk-Paz L, Kaplan I (2008) Major salivary gland output differs between users and non-users of specific medication categories. Gerodontol 25:210-216

30. Ship JA (2002) Diagnosing, managing, and preventing salivary gland disorders. Oral Dis 8:77-89

31. Scully C (2003) Drug effects on salivary glands: dry mouth. Oral Dis 9:165-176

32. Thomson WM, Chalmers JM, Spencer AJ, Williams SM (1999) The Xerostomia Inventory: a multi-item approach to measuring dry mouth. Community Dent Health 16:12-17

33. Thomson WM, Williams SM (2000) Further testing of the xerostomia inventory. Oral Surg Oral Med Oral Pathol Oral Radiol Endod 89:46-50

34. Thomson WM, Chalmers JM, Spencer AJ, Slade GD (2000) Medication and dry mouth: findings from a cohort study of older people. J Public Health Dent 60:12-20

35. Thomson WM, Chalmers JM, Spencer AJ, Slade GD, Carter KD (2006) A longitudinal study of medication exposure among older people. Gerodontology 23:205-213

36. Aps JKM, Martens LC (2005) Review: the physiology of saliva and transfer of drugs into saliva. Forensic Sci Int 150:119-131

37. Navazesh M, Christensen CM (1982) A comparison of whole mouth resting and stimulated salivary measurement procedures. J Dent Res 61:1158-1162

38. Samaranayake LP, Wilkieson CA, Lamey PJ, MacFarlane TW (1995) Oral disease in the elderly in long-term hospital care. Oral Dis 1:147-151

39. Mazengo MC, Söderling E, Alakuijala P, Tiekso J, Tenovuo J, Simell O et al (1994) Flow rate and composition of whole saliva in rural and urban Tanzania with special reference to diet, age, and gender. Caries Res 28:468-476

40. Johansson AK, Johansson A, Unell L, Ekbäck G, Ordell S, Carlsson GE (2009) A 15-yr longitudinal study of xerostomia in a Swedish population of 50-yr-old subjects. Eur J Oral Sci 117:13-19

41. Thomson WM, Poulton R, Broadbent JM, Al-Kubaisy S (2006) Xerostomia and medications among 32-years-olds. Acta Odontol Scand 64:249-254

42. Khosravani N, Birkhed D, Ekström J (2009) The cholinesterase inhibitor physostigmine for the local treatment of dry mouth: a randomized study. Eur J Oral Sci 117:209-217

43. Meurman JH, Tarkkila L, Tiitinen A (2009) The menopause and oral health. Maturitas 63:56-62

44. Handelman SL, Baric JM, Mark MS, Espeland MA, Berglund KL (1986) Prevalence of drugs causing hyposalivation in an institutionalized geriatric population. Oral Surg Oral Med Oral Pathol 62:26-31

45. Simons D, Brailsford SR, Kidd EAM, Beighton D (2002) The effect of medicated chewing gums on oral health in frail older people: a 1-year clinical trial. J Am Geriatr Soc 50:1348-1353

46. Berk L (2008) Systemic pilocarpine for treatment of xerostomia. Exp Opin Drug Metab Toxicol 4:1333-1340

47. Weber J, Keating GM (2008) Cevimeline. Drugs 68:1691-1698

48. Vissink A, Burlage FR, Spijkervet FKL, Veerman ECI, Nieuw Amerongen AV (2004) Prevention and treatment of salivary gland hypofunction related to head and neck radiation therapy and chemotherapy. Support Cancer Ther 1:111-118

49. Chambers MS, Mellberg JR, Keene HJ, Bouwsma OJ, Garden AS, Sipos T et al (2006) Clinical evaluation of the intraoral fluoride releasing system in radiation-induced xerostomic subjects. Part 1: fluorides. Oral Oncol 42:934-945 